\title{
Role of Maternal Serum Procalcitonin, Interleukin-6 and hs-C Reactive Protein in Prediciton of Subclinical (Intrauterine) Infection in Preterm Premature Rupture of Membranes
}

\author{
Amany M.E. Abd Elmegeed*, Sabah I. Abd Elreheem*, Al-Shimaa Allam Abd \\ Ellatif**, Inas Mahmoud Hamdy**, Eman El-Shohat Ebrahem*** \\ Clinical Pathology* Obstetrics and Gynecology** \\ Medical Biochemistry**** \\ Departments, Al-Azhar University \\ Faculty of Medicine for girls
}

\begin{abstract}
Objective:

To evaluate the role of procalcitonin (PCT), high senstive C-reactive protein (hs-CRP) and Interleukin-6 (IL-6) for prediction of subclinical intrauterine infection in pregnant women with preterm premature rupture of membranes.
\end{abstract}

\section{Methods:}

Twenty patients with preterm premature rupture of membranes PPROM (study group) and twenty apparently healthy pregnant women (control) group between 26-34 weeks of pregnancy were enrolled in this study.

In all cases analysis of serum procalcitonin by high performance liquid chromatography, Il-6 by ELISA method and hs-CRP by nephelometry were done. Culture of vaginal bacteria was done for study group only.

\section{Results:}

Procalcitonin levels in the PRROM group were significantly higher than in healthy pregnant women (median 1.95 versus 0.39-Interquartile range 1.375 versus 0.213 - P0.001). A significant correlation was observed between PCT and hs-CRP ( $\mathrm{r}=0.510 ; \mathrm{P} 0.031)$ and leucocytosis ( $\mathrm{r}=0.544-\mathrm{P}$ 0.013). Also IL-6 levels were significantly higher in cases of PPROM compared with control group (median 40.01 versus 5.55 - Interquartile range, 45.88 versus

4.22 P 0.001). No significant correlation was present between PCT and IL-6

\section{Conclusion:}

Determination of PCT, hs-CRP and IL-6 in mother's blood sample can be useful for diagnostics of PPROM cases suspected of intrauterine infection. However PCT more valuable and specific.

Key words:

Preterm premature rupture membranes, Procalcitonin:

Interleukin -6 , high sensitive $\mathrm{C}$-reactive protein

\section{Introduction}

Preterm premature rupture membranes (PPROM) defined as rupture of membranes before labor and prior to 37 weeks. It complicates 2-3 percent of pregnancies that have not reached 37 weeks of gestation (Bloom and Associates, 2001).

Despite recent advances in perinatal care, PPROM continues to lead to important obstetric complications beginning a highrisk period for both mother and fetus (Mateus et al., 2010; Pasquier and Doret, 2008). 
Although the assessment of various inflammatory mediators in the amniotic fluid is highly accurate in the diagnosis of amnionitis, it requires the performance of invasive amniocentesis. Moreover, amniocentesis may be difficult to perform in patients with premature rupture of membranes (PROM), because the amniotic fluid volume is often reduced (Dinaro et al., 2003). Therefore, non-invasive methods of detecting intrauterine infection are desirable.

Procalcitonin has been shown to be important, sensitive and specific marker of the severe inflammatory responses. These days, procalcitonin is believed to be more specific marker of the severity of sepsis than cytokine interleukin 6 (IL-6) and high sensitive C-reactive protein (hsCRP) (Greksova et al., 2009).

Procalcitonin a prohormone consisting of 116 amino acids, is recognized as a specific marker of generalized bacterial infections (Torbe and Czajka, 2005). In Serum of healthy individuals, it is present at less than $0.5 \mathrm{ng} / \mathrm{ml}$; but in conditions leading to systemic inflammatory response syndrome or sepsis, it rapidly increases to high levels (Struck et al., 2002).

The short half life of PCT (20-24hours) enables not only rapid detection of infection but also titration of response to the treatment (Tunner et al., 2006). PCT concentration increases in the serum within 2 to 3 hours, of the beginning of infection, peaking by $6-12 \mathrm{~h}$ and returning to normal concentrations within two days. Its production is induced by endotoxin and by pro-inflammatory cytokines, tumor necrosis factor- $\alpha(\mathrm{TNF} \alpha)$, interleukin I interleukin 2 and interleukin 6 (Vazzdwar, 2005).

IL-6 is a polypeptide composed of 183185 amino acids and molecular weight of approximately 19 to $30 \mathrm{KDa}$ depending on glycosylation. IL-6 is produced by $\mathrm{T}$ and B cells, fibroblasts, endothelial cells, monocytes and macrophages (Oleszczuk et al., 1997). IL-1, tumor necrosis factor (TNF) interferon, viruses and bacterial toxins are factors which stimulate the production of IL-6.

CRP is a member of the class of acutephase reactant, as its levels rise dramatically during inflammatory processes occurring in the body. This increment is due to a rise in plasma concentration of IL-6 which is produced predominantly by macrophages as well as adipocytes (Lau et al., 2005). It rises above normal limits within 6 hours and peaks at 48 hours. Its half-life is constant and therefore its level is mainly determined by the rate of production (StOnge et al., 2009).

Aim of the study

The purpose of the present study was to evaluate the role of PCT, hs-CRP and IL-6 for prediction of subclinical intrauterine infection in cases of preterm premature rupture of membranes.

Patients and Methods:

The study was carried out at Al-Zahraa University hospital, faculty of medicine for Girls, department of obstetrics and gynecology and clinical pathology between July 2009 and June 2010 Fourty women with singleton pregnancies were included in this study after providing oral informed consent.

- $\quad$ Their age ranged between (18-40 years).

- $\quad$ Gestational age between (26-34) weeks was based on the last menstrual period and was confirmed by early second trimester ultrasonographic examination.

The study population was divided into two groups as shown in table (1).

Group 1 (study group) consisted of 20 patients with preterm premature rupture of membranes without uterine contractions at the onset of PPROM (None of them showed clinical signs of infection or any other fetal or maternal complications at admission.

All patients received antibiotics, corticosteroids with bed rest and fetal heart monitoring and uterine activity assessment was performed twice daily. Rupture of membranes was diagnosed by history, sterile speculum examination confirming fluid leakage from the cervical canal or pooling of fluid in the posterior vaginal fornix and positive amnio test. 
Ultrasound was done to confirm gestational age and measure amniotic fluid index and follow up.

Group 11 (control) consisted of 20 healthy pregnant women at the same gestational age with intact membrane and without uterine contractions. Non of them had other diseases or obstetric complications.

- $\quad$ PCT, IL-6, hs-CRP, WBC were done for all patients and controls.

- Vaginal fluid culture for aerobic and anaerobic bacteria was done for patients only.

- Fetal outcome was evaluated by a neonatologist.

- Detection of clinical chorioamnionitis if present.

Sampling: for patients, venous blood samples were collected within four hours of rupture of membranes before administration of any drugs. For controls, samples were collected during routine antenatal visits. Five $\mathrm{ml}$ of venous blood was obtained from each patient and control.

Two $\mathrm{mL}$ were dispensed into a tube containing EDTA for complete blood count (for detection of WBC) and the remaining three portions were dispensed in a plain tube and left to clot, then serum was separated and stored at-20 until used for PCT, hs CRP and IL-6 detection. WBCs count was done on systmex apparatus model KXZI.

A-quantitative measurement of procalcitonin was done by means of high performance liquid chromatography (HPLC) model waters. Standard used was Human Recombinant procalcitonin $(0.1 \mathrm{ng} / \mathrm{ml})$ (Shenadoah biotech. Inc USA). Column used was PRP-3 (Gradient protein and peptide separations.)

A quantitative measurement of serum IL-6 was done by ELISA technique using AviBion human IL-6 ELISA kite supplied by orgenium, FINLAND.

(REF:IL060d), with sensitivity $<7 \mathrm{pg} / \mathrm{ml}$.Inter-assay precision and intraassay precision were $<8.6 \%$ and $<9.4 \%$. The results were read on ELISA reader model SLT/spectera.
hs-CRP was measured and determined quantitively by means of particles enhanced immunonephelometry using the BN11 system DNA

BEHRING, where polystyrene particles coated with antibodies to CRP respectively are aggregated when mixed with sample containing CRP, these aggregation scatter a beam of light passed through the mixture, the intensity of scattered light is proportional to concentration of the relevant protein in the samples, the results were evaluated by comparison with a standard of known concentration. Vaginal discharge was collected under complete aseptic condition; a sterile swab was used to collect the specimen from vagina to be examined by wet preparation, dry smear, and to-do vaginal culture, for aerobic and anaerobic bacteria.

\section{Statistical analysis was done by:}

T-test, Mann-Whitney test, Chi-squared test, P-values and Person correlation by SPSS version 17, median was used due to wide distribution of data.

$\mathrm{P}$ value $>0.05$ is considered nonsignificant.

$\mathrm{P}$ value $\leq 0.05$ is considered significant $P$ value $\leq 0.01$ is considered highly significant 
Role of Maternal...

\section{Results}

Table (1): Demographic and clinical characteristics of the study and control group.

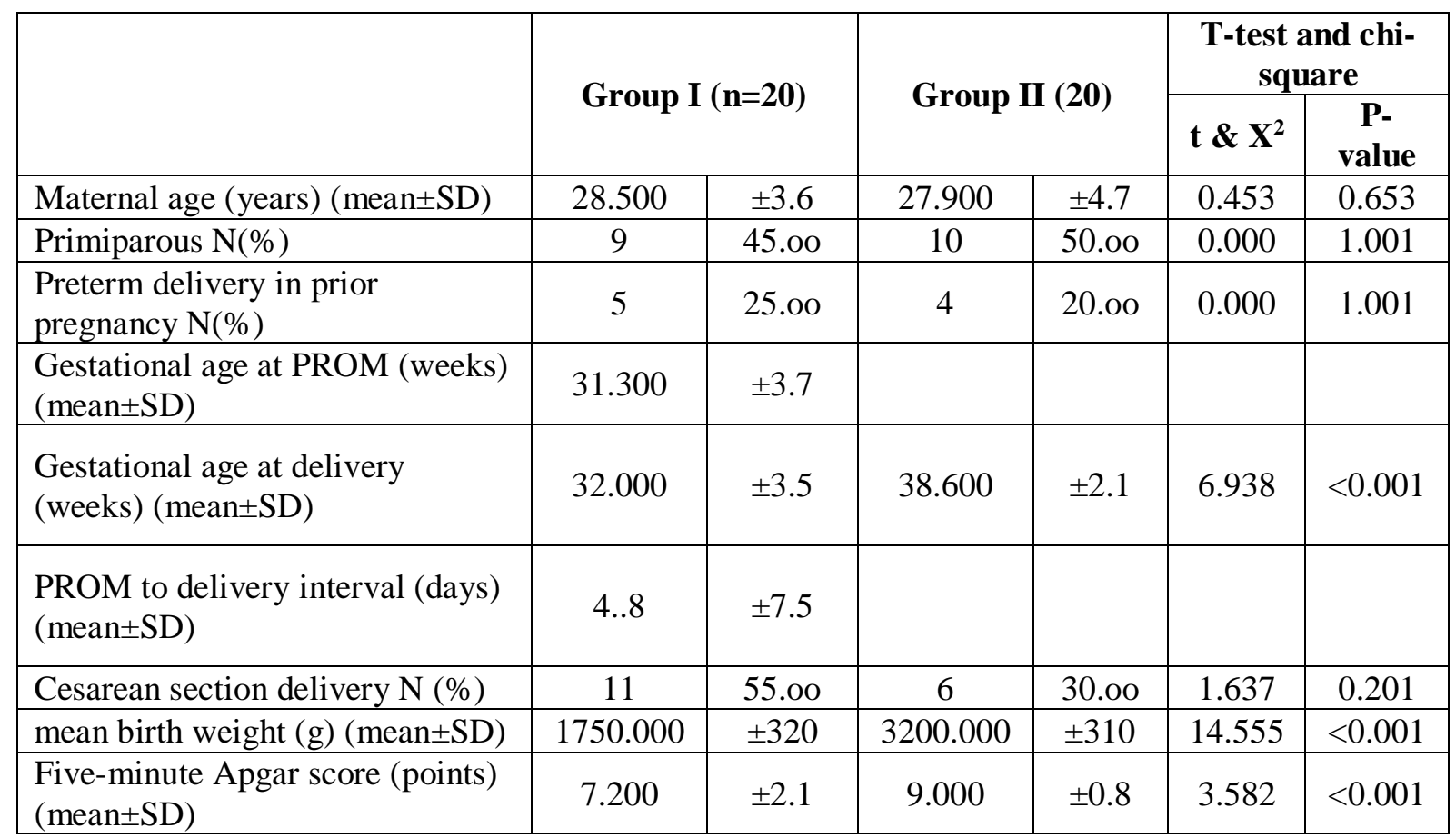

Table (2): Maternal serum PCT compared with other markers of interauterine infection.

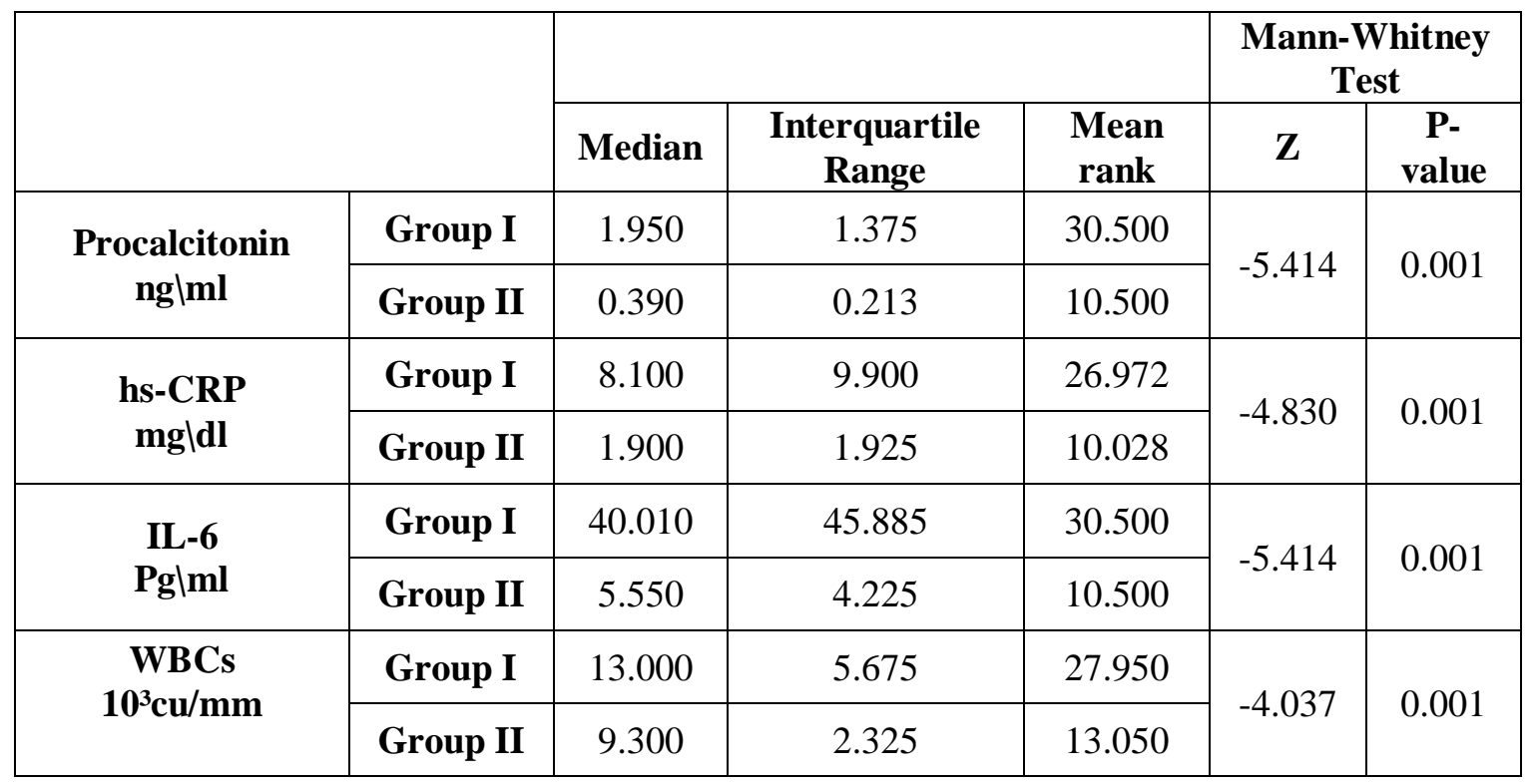


Amany Abd Elmegeed....et al

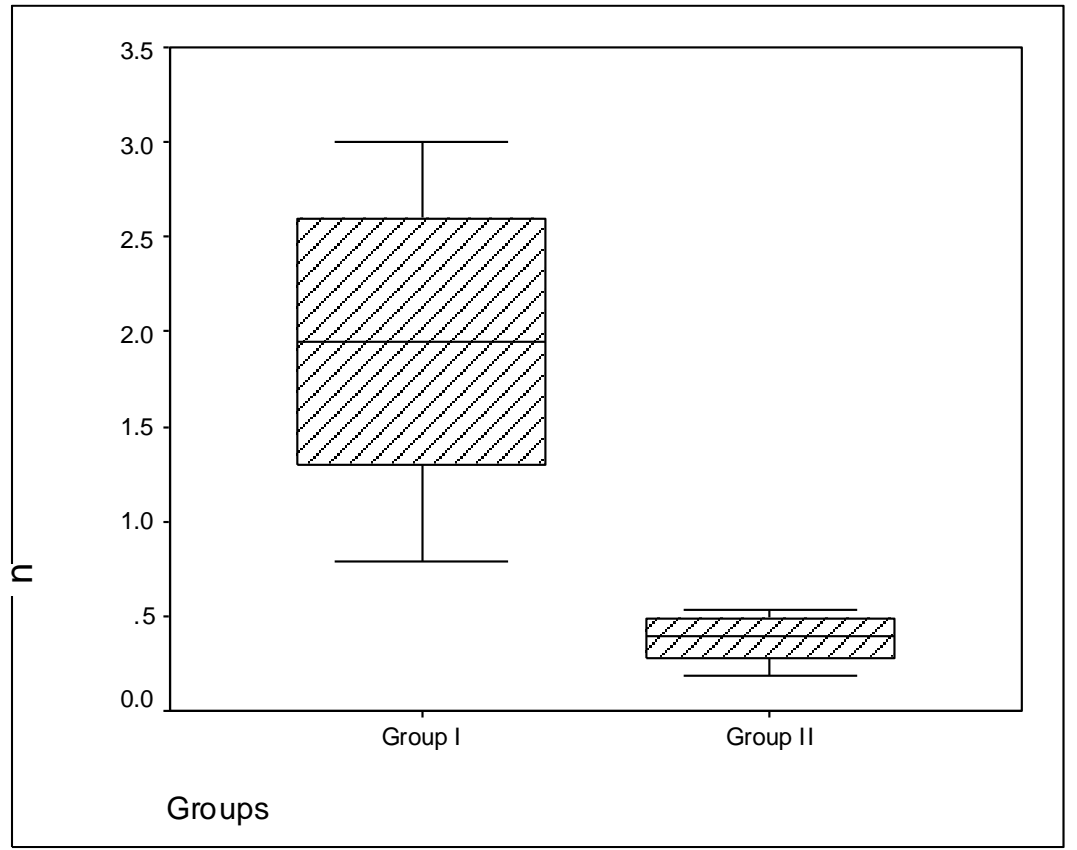

Fig (1): PCT in the study (group 1) and control ( group 11)

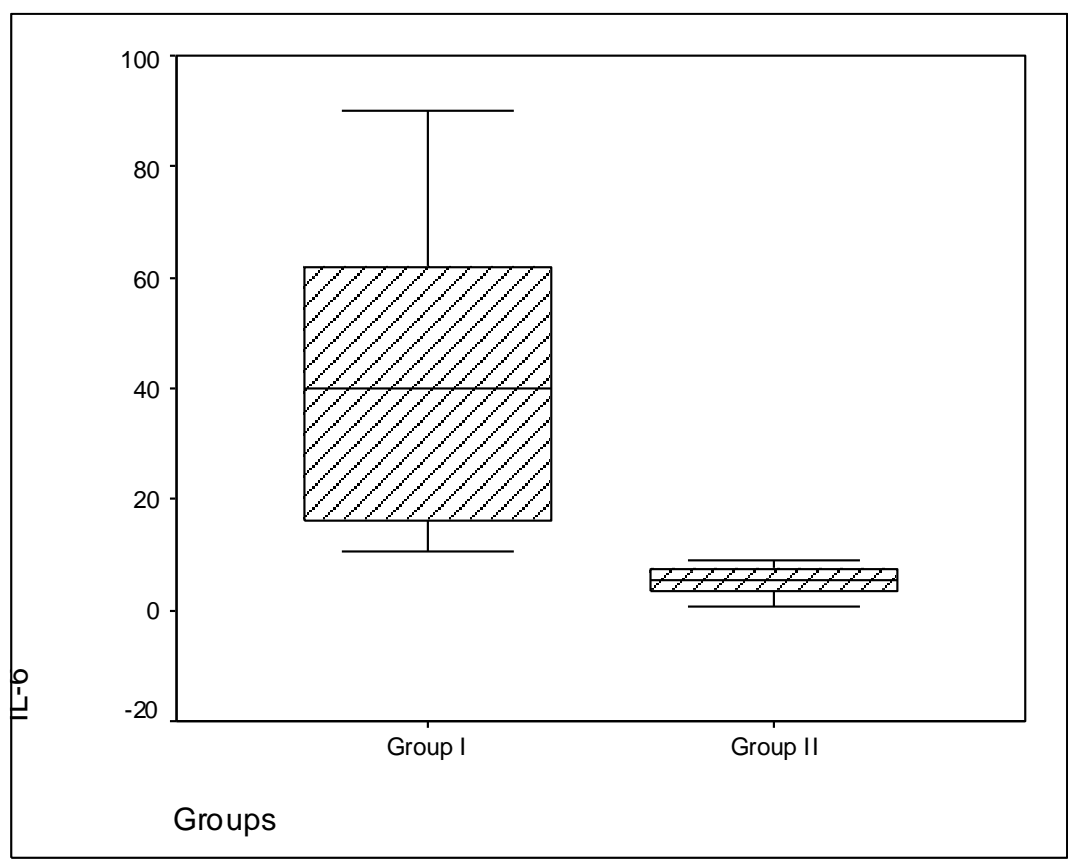

Fig. (2) IL-6 in the study group (group 1) and control ( group 11) 
Table (3): Correlation between PCT and other markers of intrauterine infection.

\begin{tabular}{|c|c|c|c|c|}
\hline & & Procalcitonin ng/ml & hs CRP & IL-6 \\
\hline \multirow{2}{*}{$\begin{array}{c}\text { hs CRP } \\
\text { mgldl }\end{array}$} & $\mathbf{r}$ & 0.510 & & \\
\cline { 2 - 5 } & P-value & $0.031^{*}$ & & \\
\hline $\begin{array}{c}\text { IL-6 } \\
\text { Pglml }\end{array}$ & $\mathbf{r}$ & 0.210 & -0.015 & \\
\hline & P-value & 0.373 & 0.951 & \\
\hline $\begin{array}{c}\text { WBCs } \\
\mathbf{1 0} \mathbf{c} \mathbf{c u} / \mathbf{m m}\end{array}$ & $\mathbf{r}$ & -0.544 & -0.315 & -0.199 \\
\cline { 2 - 5 } & P-value & $0.013^{*}$ & 0.203 & 0.400 \\
\hline
\end{tabular}

Table (4): Correlation between markers of intrauterine infection, and PPROM to delivery interval.

\begin{tabular}{|c|c|c|c|c|}
\hline & & PCT & CRP & IL-6 \\
\hline \multirow{2}{*}{$\begin{array}{c}\text { PPROM to delivery interval (days) } \\
\text { (correlation) }\end{array}$} & $\mathbf{r}$ & 0.220 & 0.105 & 0.813 \\
\cline { 2 - 5 } & P-value & 0.350 & 0.644 & 0.001 \\
\hline
\end{tabular}

Serum PCT level was significantly higher in (PPROM) group than in healthy control group $(\mathrm{P} 0.001)$ table-2.

Also we found that the levels of hs-CRP, IL-6 and WBCs significantly increased in the study group compared with the control group (P0.001) table 2.

Our results showed that serum PCT correlated positively with hs-CRP and WBS (r 0.510 P 0.031 and $r 0.544$ P0.013 respectively). However PCT levels were not correlated with IL-6 (r 0.210 P0.373) (table 3 ).

In our study group there was significant decrease in gestational age at delivery $(\mathrm{P}<0.001)$ fetal birth weight $(\mathrm{P}<0.001)$ and five minute Apgar score $(\mathrm{P}<0.001)$. There was no significant increase in the percentage of cesarean section in the study group in comparison to the control group table (1)

PPROM to delivery interval showed a positive correlation with IL-6 (r 0.813 P 0.001 ) table (4).

Four cases of PPROM showed a positive vaginal fluid culture. Two cases were Candida albicans and two cases were streptococcus B.

\section{Discussion}

Primary intra-amniotic sub clinical infection is one of the main causes of PPROM and the prompt identification of such cases is necessary for choosing the proper mode of management (Torbe and Czajka, 2005).

The results of our study showed that maternal serum PCT concentrations were significantly higher in cases of PPROM compared to the control (1.95 versus 0.39 P 0.001),confirming the hypothesis about the infectious etiology of rupture of membranes.

This is in agreement with (Torbe, 2007), who found that PCT values were significantly higher in PPROM in comparison to preterm cases with intact membranes in approximate gestational age (P.002).

Also Ginekol (2010), concluded that PCT has the highest predictive value in predicting clinical symptoms of intra amniotic infection and neonatal infection in pregnant women with premature rupture of membranes, similar results were obtained by Kuyumcuoglu et al. (2010). As regard hs-CRP, our study found a statistically significant higher maternal serum hs-CRP in cases of PPROM compared with healthy control group (8.1 versus $1.9 \mathrm{P} 0.001$ ).

This is in agreement with (Greksova et al., 2009 and Ginekol, 2010), who observed higher concentration of CRP in mother's blood samples with PROM compared with intact membrane.

The present study also showed a significant correlation between PCT and 
hs-CRP (r $0.510 \mathrm{P} 0.031$ ) and leucocytosis (r 0.544 P 0.013).

Although both PCT and hs-CRP increases in cases of PPROM, PCT is more valuable and specific marker of inflammatory response. It starts to increase in serum earlier than (hs-CRP) from 2 to 3 hours for PCT however hs-CRP rises above normal limits within 6 hours. Also PCT is considered as specific marker of bacterial infection .

While the (hs-CRP) test is not specific enough to diagnose a particular disease, it does serve as a general marker for infection and inflammation, thus alerting medical professionals that further testing and treatment may be necessary (St-Onge et al., 2009).

Interleukin-6 increases rapidly and peaked at 6 hours. There was half life of 15 hours and rapid return to normal concentration (Ginekol, 2010),

In the present study maternal serum IL-6 was significantly higher in women with PPROM (40.01) than in healthy control group (5.55) (P0.001).

This is in agreement with Hatzidaki et al. (2005), who concluded that IL-6 in maternal blood was indicative of intrauterine environmental threats and might be used to identify pregnancies where intervention would be appropriate. Similar results were obtained by Murtha et al. (2007) and Ginekol (2010).

We did not find correlation between PCT and IL-6.

Four of twenty patients (20\%) of PPROM positive cultures of vaginal fluid were detected.

In our study we did not observe clinical signs of infection in any of the cases of PPROM.

We found that PPROM to delivery interval was positively correlated with IL-6 ( $\mathrm{r}$ 0.813-P0.001). This is similar to Ginekol (2010) in his study.

\section{In conclusion}

Our study suggests that measurement of PCT, hs-CRP and IL-6 in mother's blood sample can be used as markers for prediction of sub clinical intrauterine infection. However PCT is more valuable, specific and earlier marker of sepsis than CRP and IL-6. Further studies are required to determine the relative contribution of PCT in the mechanisms of PPROM.

\section{References}

Bloom SL, Yost NP, Mclntire DD, et al. (2001): Recurrence of preterm birth in singleton and twin pregnancies. Obstet Gynecol., 98:379

Di Naro E, Ghezzi F, Raio L et al. (2003): Creactive protein in vaginal fluid of patients with preterm premautre rupture of membranes Acta Obstet Gynceol Scand., 82: 1072-1079 Ginekol Pol (2010): Usefulness of PCT, IL-6, CRP measurement in the prediction of intra amniotic infection and newborn status in pregnant women with premature rupture of membrane, Clinical perinatology; 81 (5): 33641.

Greksova K., Parrak V., Chovancova D, Stencl P, Oravec J, Marsik L et al. (2009): Procalcitonin, nepterin and $C$-reactive protein in diagnostics of intrauterine infection and preterm delivery. Bratisl lek listy, 110 (10): 623-626.

Hatzidaki E., Gourgiotis D, Manoura A., Korakaki E et al. (2005): Interleukin-6 in preterm premature rupture of membranes as an indicator of neonatal outcome. Acta obstet Gynecol scand; 84 (7): 632-8.

Kuyumcuoglu V, Kangal K, Guzel AL, Celiky (2010): Clinical significance of procalcitonin in cervico-vaginal secretions of women with preterm rupture of membranes. Clin Exp. Obstet Gynecol., 37 (4): 319-21.

Lau DC, Dhillon B, Yan H, Szmitko PE, Verma $S$ (2005): "Adipokines: molecular links between obesity and atherosclerosis. Am J physiol heart circ physiol., 288 (5): H2031-41. Mateus J, K. Fox, S. Jain, S. Jain, R. Latta and J. Cohen (2010): Preterm premature rupture of membranes: Clinical outcomes of late-preterm infants. Clin. Pediatr (phila), 49:60-65.

Murtha AP, Sinclair T, Hauser ER, Swamy GK et al. (2007): Maternal serum cytokines in preterm premature rupture of membranes obstet. Gynecol., 109 (1): 121-7.

Oleszczuk J., Wawrzycka B., Maj G (1997):

Interleukin-6 and neopterin levels in serum of patients with preterm labor with and without infection European. J obstet Gynecol and Reproductive Biology, 74:27-30.

Pasquier JC and M. Doret (2008): Monitoring of the Latency period after a preterm premature rupture of the fetal membranes: Literature review. J Gynecol. Obstet. Biol. Reprod., 37:568-578. 
ST-Onge MP., Zhang S., Darnell B., Allison $D B$ (2009): Baseline serum c-reactive protein is associated with lipid responses to low-fat and high-polyunsturated fat diets. J. Nutr., 139 (4): 680-3.

Struck P., de Almeida, A. Bergmann and N.G. Morgen-thaler (2002): "High

concventrations of procalcitonin but not mature calcitonin in normal human milk" Hormone and metabolic Research, 34, (8): 460-465

Torbe A and Czajka R (2005): Procalacitonin in cervico-vaginal secretion in pregnancies complicated by preterm labo-0a preliminary report. Eur J obstet Gynecol Reprod Bil., 116: 177-181.
Torbe A (2007): Maternal plasma procalcitonin concentrations in pregnancy complicated by preterm premature rupture of membranes. Hindawi Publishing corporation. Mediators of inflammation. Article ID 35782, 5

Tunner D, Hammerman C, Rudensty B et al. (2006): Procalcitonin in preterm infants during the first few day of life: introducing an age related nomogram. Arch dis. Child fetal neonatal., Ed; 91: F283-F286.

Vazzadwar R, Pina-Radrigues E., Puppala BL et al. (2005): Procalcitonin as a screening test for late-onset sepsis in preterm very low birth weight infants. J perinatol., 25: 397-402. 


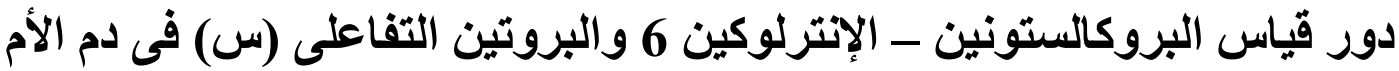

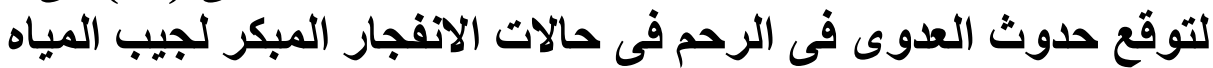

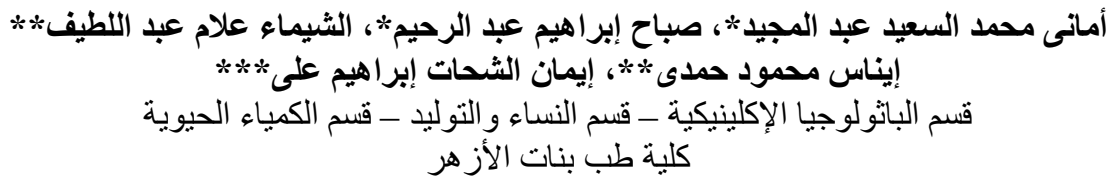

الـهدف من البحث:

دور قياس البروكالستونين - الإنترلوكين 6 و البروتين التفاعلى (س) فى دم الأم لتوقع حدوث العدوى فى الرحم فى حالات الانفجار المبكر لجيب المبنياه

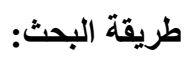

اثتملت الدر اسة على 20 حالة حمل تعانى من انفجار مبكر لجيب المياه مجموعة الدراسة (المجمو عة الأولى)

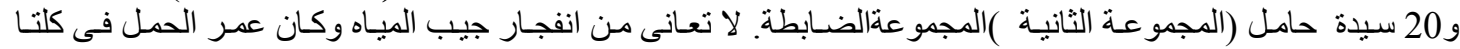

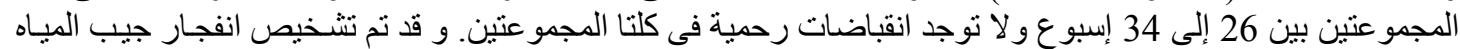

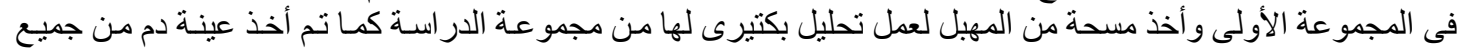



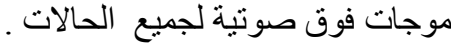

وقد استنتجت الار اسة ما يلحي:

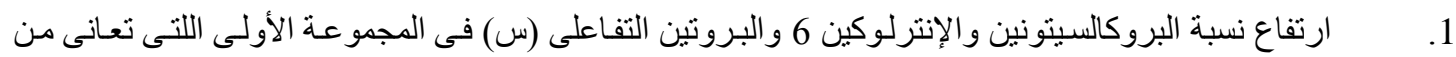

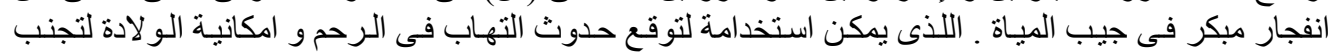
حدوث مضاعفات للام و الجنين.

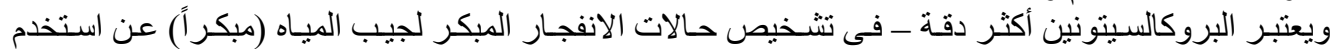
الإنترلوكين 6 و البروتين التفاعلى (س). 